\title{
A evolução biológica em produções audiovisuais na formação inicial de professores
}

\section{de Ciências e Biologia}

Biological Evolution in audiovisual productions in the initial training of Science and Biology

teachers

Evolución Biológica en producciones audiovisuales em la formación inicial de enseñantes de Ciencia y Biología

Recebido: 15/06/2021 | Revisado: 23/06/2021 | Aceito: 24/06/2021 | Publicado: 11/07/2021

\author{
Luís Gustavo da Conceição Galego \\ ORCID: https://orcid.org/0000-0002-6081-2700 \\ Universidade Federal do Triângulo Mineiro, Brasil \\ E-mail: luis.galego@uftm.edu.br \\ Sávio Cunha Costa \\ ORCID: https://orcid.org/0000-0001-8485-0560 \\ Universidade Federal de Goiás, Brasil \\ E-mail: saviocunhacosta@gmail.com
}

\begin{abstract}
Resumo
Uma alternativa para o ensino da evolução biológica, e, em particular, da evolução humana é o uso do cinema em sala de aula, tanto para ilustrar um determinado conteúdo conceitual, quanto para instrumentalizar os discentes no processo de produção audiovisual no qual múltiplas habilidades são requeridas até a finalização deste recurso imagético. Com o objetivo de investigar a construção do conhecimento sobre biologia evolutiva e evolução humana considerando a abordagem do cinema em sala de aula a partir de produções audiovisuais de licenciandos do curso de Ciências Biológicas de uma universidade pública brasileira, foram selecionadas dez produções com temáticas relacionadas à evolução humana para as quais foram analisados elementos da gramática do cinema, sobretudo dos planos cinematográficos e seus desdobramentos na geração de sentido a partir de uma análise semiótica inspirada em Peirce. A maioria das produções apresentou um predomínio de planos fechados, o que indica uma aproximação com o discurso científico e a maioria dos conceitos utilizados pelos discentes se aproximou da construção científica sobre a evolução. Os resultados aqui obtidos ainda indicam que o uso desses vídeos como recurso didático é algo possível, já que apresentam características necessárias a um filme com intenções pedagógicas.
\end{abstract}

Palavras-chave: Cinematografia; Evolução humana; Ensino de evolução.

\begin{abstract}
An alternative to teaching biological evolution, and in particular human evolution, is the use of cinema in classroom, both to illustrate a certain conceptual content, how much to instrumentalize the students in the audiovisual production process in which multiple skills are required until the completion of this imagery resource. In order to investigate the construction of knowledge about evolutionary biology and human evolution in audiovisual productions of undergraduate students of the Biological Sciences course of a Brazilian public university, ten productions were selected with themes related to human evolution for which elements of the grammar of cinema were analyzed, especially the cinematographic plans and their unfolding in the generation of meaning from a semiotic analysis inspired by Peirce. Most of the productions presented a predominance of closed plans, which indicates an approximation with the scientific discourse and most of the concepts used by the students approached the scientific construction on evolution. The results obtained here also indicate that the use of these videos as a didactic resource is possible, since they present characteristics necessary to a film with pedagogical intentions.
\end{abstract}

Keywords: Cinematography; Human evolution; Teaching of evolution.

\section{Resumen}

Una alternativa a enseñar la evolución biológica, y en particular la evolución humana, es el uso del cine en el aula, tanto para ilustrar un cierto contenido conceptual, cómo instrumentalizar a los estudiantes en el proceso de producción audiovisual en el que se requieren múltiples habilidades hasta la finalización de este recurso de imágenes. Con el fin de investigar la construcción de conocimiento sobre biología evolutiva y evolución humana en producciones audiovisuales de estudiantes de pregrado del curso de Ciencias Biológicas de una universidad pública brasileña, se seleccionaron diez producciones con temas relacionados con la evolución humana para qué elementos de la gramática del cine fueron analizados, especialmente los planes cinematográficos y su despliegue en la generación de significado 
a partir de un análisis semiótico inspirado por Peirce. La mayoría de las producciones presentaron un predominio de planos cerrados, lo que indica una aproximación con el discurso científico y la mayoría de los conceptos utilizados por los estudiantes se acercaron a la construcción científica sobre la evolución. Los resultados obtenidos aquí también indican que el uso de estos vídeos como recurso didáctico es posible, ya que presentar las características necesarias para una película con intenciones pedagógicas.

Palabras clave: Cinematográfia; Evolución humana; Enseñaza de la evolución.

\section{Introdução}

A produção de recursos didáticos é um desafio ao trabalho do professor, que se integra ao processo de se tornar professor é influenciado por uma diversidade de fatores que acompanham o sujeito ao longo de sua trajetória (Borges et al., 2020). O cinema e seus desdobramentos audiovisuais pode ser uma ferramenta valiosa para ações de ensino. A experiência com a elaboração de vídeo aulas a partir de conhecimentos sobre interdisciplinaridade, apresentada por Veiga et al. (2020), por exemplo, ilustra uma aplicação do audiovisual na formatação do conhecimento em uma ação da realidade. Dessa forma, o processo de se tornar professor, em junção com as diferentes experiências com o cinema que os sujeitos vivenciaram ao longo da sua história podem convergir em práticas nas quais o fazer cinematográfico ocorra (Migliorin, 2015; Borges et al., 2020).

O cinema apresenta múltiplos aspectos técnicos, estéticos e multidisciplinares que o tornam uma ferramenta educativa que possibilita retratar diversos domínios da vida cotidiana (Silva et al., 2021). De fato, filmes podem ser utilizados como recursos didáticos recorrentes no ensino de ciências e biologia (Sousa, Cicuto \& Lucchese, 2020). Uma das áreas das ciências biológicas mais importantes tanto para cientistas como para o cidadão no seu cotidiano, em virtude do seu aspecto unificador e articulador do conteúdo biológico é a evolução (Scheifele, Corazza \& Justina, 2020). Professores de ciências e biologia devem compreender os conceitos de evolução biológica e as maneiras como estes podem ser ensinados e as produções audiovisuais podem contribuir de maneira promissora para essa finalidade.

A nossa hipótese inicial em relação à investigação aqui realizada era de que licenciandos apresentassem produções audiovisuais com conteúdos conceituais de evolução biológica congruentes com os conceitos científicos, além de estrutura imagética que utilize de elementos semióticos, mesmo que não intencionalmente. Considerando essas questões e a hipótese $a$ priori, o objetivo deste trabalho foi verificar a construção de conhecimentos sobre Evolução Biológica em futuros professores de Ciências e Biologia a partir de produções audiovisuais elaboradas por eles. Ademais, em relação às produções audiovisuais elaboradas pelos futuros professores, pretendeu-se avaliá-las quanto a sua construção estética e conceitual, levantar as escolhas de gêneros mais recorrentes, bem como o uso da gramática da linguagem audiovisual e sua vinculação com a Evolução Biológica, propiciar a elaboração de um material didático que pode ser socializado de forma multinível (desde a sala de aula até à Internet).

\section{Metodologia}

A utilização de produções audiovisuais em sala de aula constitui um recurso didático relevante, uma vez que esse tipo de produto midiático agrega o fascínio pelo cinema e a facilidade de acesso aos filmes (Abud, 2003). De fato, o cinema é utilizado nas escolas desde os anos 20 , com enfoque principal na ilustração de conceitos, na reprodução da informação e na instrução (Barros, 1997). Essa perspectiva tradicional de ensino pode ser superada a partir da implementação de outras abordagens do cinema em sala de aula, que incluem a produção audiovisual pelos alunos (Carvalho, 2003; Napolitano, 2011; Galego \& Pereira, 2020). A proposta aqui apresentada ilustra essa potencialidade do cinema-educação, e foi desenvolvida em uma disciplina de um curso de licenciatura, voltada para o ensino da evolução biológica. Nessa proposta, os alunos, em grupos, produzem um recurso audiovisual com temas de biologia evolutiva para o qual devem elaborar um roteiro, realizar as 
filmagens, editar as cenas e socializar o produto com a turma e disponibilizá-lo no Youtube para que outras pessoas possam acessá-lo.

Os discentes de um curso de licenciatura em ciências biológicas têm contato direto com conteúdos conceituais de Evolução Biológica em disciplinas obrigatórias e eletivas. Em todas elas, há a proposição de produções audiovisuais como atividade avaliativa, que podem ser desenvolvidas em grupos de até cinco alunos. Esse desenvolvimento em grupos possibilita que diferentes competências e habilidades que cada componente do grupo apresente, tais como capacidade de roteirizar, dirigir, editar, atuar, possam contribuir para a construção de um produto único no qual todos podem se sentir responsáveis pela sua organicidade (Fantin, 2014; Galego \& Pereira, 2020). Essas produções consistem na elaboração de um roteiro, filmagem e edição de uma produção audiovisual do tipo curta-metragem, obtendo um produto final com até três minutos.

A elaboração do roteiro é feita a partir da leitura e interpretação de um artigo científico sobre Biologia Evolutiva. A condição é que as questões científicas mais importantes, apresentadas no artigo sejam selecionadas e reorganizadas em informações que possam ser comunicadas por meio de uma produção audiovisual e que mesmo aqueles indivíduos que não tenham domínio da terminologia científica consigam compreender a mensagem veiculada pelo filme.

O próximo passo é o planejamento e a execução das filmagens para os quais recomenda-se que os discentes apliquem técnicas cinematográficas conforme sugerido por Galego et al. (2014) e Pereira et al. (2014) e utilizem equipamentos e programas computacionais que já dispõem._Dessas produções, foram selecionadas dez (Tabela 1) para comporem o corpus de análise deste trabalho. Todos os sujeitos que participaram das gravações e tiveram suas imagens capturadas nas produções audiovisuais assinaram um termo de autorização do uso da imagem, no qual foram descritos a natureza da produção e para qual finalidade a filmagem foi realizada.

Tabela 1. Produções audiovisuais realizadas por aluno da Licenciatura em Ciências Biológicas de uma universidade pública brasileira que abordam aspectos da evolução humana, selecionadas para análise neste trabalho.

\begin{tabular}{|c|c|c|c|}
\hline Título & Tema & Duração & Link para o Youtube \\
\hline Quem dá mais? & $\begin{array}{l}\text { A definição de gênero pelas pessoas atende padrões } \\
\text { corporais esperados em homens e mulheres? }\end{array}$ & 13 '59', & https://youtu.be/H7h_0FT5-NM \\
\hline Hominideos planet. & $\begin{array}{l}\text { A questão evolutiva relacionada à perda dos pelos em } \\
\text { humanos. }\end{array}$ & $5 ’ 21$, & https://youtu.be/5ENuUyJxEeE \\
\hline $\begin{array}{l}\text { Uma pequena longa } \\
\text { história. }\end{array}$ & $\begin{array}{l}\text { Vídeo música em stop motion sobre a origem e } \\
\text { evolução do homem. }\end{array}$ & $4^{\prime} 07^{\prime}$ & https://youtu.be/SzRfRkRMSWo \\
\hline $\begin{array}{l}\text { Manequin challenge } A \\
\text { teoria sintética evolutiva }\end{array}$ & $\begin{array}{l}\text { A teoria sintética evolutiva explicitada a partir do } \\
\text { meme Manequin Challenge. }\end{array}$ & $69^{\prime}$ & https://youtu.be/Kko5EiW4Eto \\
\hline $\begin{array}{l}\text { Retrato molecular do } \\
\text { Brasil. }\end{array}$ & A composição genética das populações brasileiras. & $4 ’ 21{ }^{\prime}$ & https://youtu.be/Jr1ToC9rTCg \\
\hline $\begin{array}{l}\text { Evolução do pensamento } \\
\text { humano. }\end{array}$ & O que torna humanos o Homo sapiens?. & $41^{\prime \prime}$ & https://youtu.be/R6fD_QIRWF4 \\
\hline Os primeiros americanos. & $\begin{array}{l}\text { As migrações pré-históricas e a colonização das } \\
\text { Américas pelos humanos. }\end{array}$ & 8'03', & https://youtu.be/854YPcSe-po \\
\hline A evolução da barba. & $\begin{array}{l}\text { A relação entre a barba humana e a evolução por } \\
\text { seleção sexual. }\end{array}$ & 2'11'” & https://youtu.be/pGNJkeTYTg4 \\
\hline $\begin{array}{l}\text { Homossexualidade e a } \\
\text { Bíblia. }\end{array}$ & A relação homossexualidade, bíblia e evolução. & $28^{\prime}{ }^{\prime}$ & https://youtu.be/1mLcXz7apI4 \\
\hline Dedos e esportes. & $\begin{array}{l}\text { A relação entre a proporção dos segundo e quarto } \\
\text { dedos e a habilidade masculina em esportes. }\end{array}$ & 3’24', & https://youtu.be/_PaKL6w01Q0 \\
\hline
\end{tabular}

Fonte: Autores. 
Após a seleção das produções, realizou-se a etapa de levantamento bibliográfico no qual foram utilizados os seguintes descritores e suas combinações: cinema; evolução biológica; formação inicial de professores; entre outros. Versões em inglês dos descritores também foram incorporadas à pesquisa. Foram consideradas as produções dos últimos vinte anos (2000-2020).

A terceira etapa consistiu em uma análise das imagens em movimento inspirada na proposta por Merrel (2012), que faz uma atualização da teoria semiótica de Peirce, e a seleção de signos cinematográficos foi aquela proposta por Cruz \& Galego (2020), na qual os planos de enquadramento atuam como índices (primeridade), o contexto da cena permite a captação da dimensão narrativa (secundidade), que, por meio de uma interação multinível, geram o sentido (terceiridade). Os dados da análise semiótica foram então confrontados com conceitos e evolução biológica contidos em fontes primárias, e a dialogicidade entre a produção audiovisual e os conceitos científicos sobre evolução biológica foi discutida.

\section{Resultados e Discussão}

A Evolução Biológica é considerada um eixo central e integrador de conteúdos da biologia, pois a sua compreensão se faz necessária no entendimento de uma série de conhecimentos desta ciência (Goedert et al., 2003), tornando assim componente indispensável no ensino de Biologia e Ciências na educação básica e também no ensino superior.

Apesar da relevância do ensino de Evolução Biológica, majoritariamente, por ser um tema-chave para a compreensão de diversos fenômenos biológicos, além do respaldo por meio dos norteadores e diretrizes da educação básica e superior brasileira, pesquisas têm demonstrado que os conteúdos não têm recebido atenção pelos professores de ciências e biologia, considerado um dos temas mais complexos e polêmicos do currículo, o que torna a formação inicial de professores de ciências e biologia um momento chave para a fundamentação de conceitos e reflexões acerca desse tema. Além disso, conforme as diretrizes nacionais para os cursos de Ciências Biológicas:

“[...] O estudo das Ciências Biológicas deve possibilitar a compreensão de que a vida se organizou através do tempo, sob a ação de processos evolutivos, tendo resultado numa diversidade de formas sobre as quais continuam atuando as pressões seletivas (Brasil, 2001, p. 1)".

Assim, "os conteúdos básicos deverão englobar conhecimentos biológicos e das áreas das ciências exatas, da terra e humanas, tendo a evolução como eixo integrador" (BRASIL, 2001, p. 5). A pesquisa aqui apresentada promove uma reflexão sobre o ensino de biologia evolutiva na formação inicial de docentes, a partir da análise de produções realizadas por licenciandos do curso de Ciências Biológicas de uma universidade pública brasileira. A análise dos planos cinematográficos nessas produções (Tabela 2) indicou um predomínio de enquadramentos fechados em relação ao abertos. 
Tabela 2. Tempo (em segundos) de planos abertos e fechados (primeiridade) e sua relação com a narrativa (secundidade) e sentidos gerados (terceiridade) em cada uma das produções audiovisuais de licenciandos do curso de Ciências Biológicas de uma universidade pública brasileira.

\begin{tabular}{|c|c|c|c|c|}
\hline $\begin{array}{l}\text { Produção } \\
\text { audiovisual }\end{array}$ & $\begin{array}{l}\text { Planos } \\
\text { Abertos }\end{array}$ & $\begin{array}{l}\text { Planos } \\
\text { Fechado } \\
\quad \text { s }\end{array}$ & $\begin{array}{c}\text { Narrativa } \\
\text { (secundidade) }\end{array}$ & $\begin{array}{c}\text { Sentido } \\
\text { (terceridade) }\end{array}$ \\
\hline Quem dá mais? & 151 & 530 & $\begin{array}{l}\text { Uma garota e um garoto se preparando para } \\
\text { uma festa, na qual há a discussão de uma } \\
\text { pesquisa que relaciona o formato do corpo } \\
\text { (morfologia) com as escolhas pelo sexo oposto } \\
\text { e o significado evolutivo delas. }\end{array}$ & $\begin{array}{l}\text { A perspectiva biologizante das escolhas sexuais, na } \\
\text { qual aspectos mais amplos da sexualidade são } \\
\text { ignorados. }\end{array}$ \\
\hline Hominídeos planet. & 17 & 326 & $\begin{array}{l}\text { Telejornal que discute aspectos ecológico- } \\
\text { evolutivos da perda de pelos nos humanos. }\end{array}$ & $\begin{array}{l}\text { Os humanos atuais gradativamente perderam seus } \\
\text { pelos em resposta adaptativa à seleção natural } \\
\text { produzida pelas mudanças climáticas ao longo da } \\
\text { evolução. }\end{array}$ \\
\hline $\begin{array}{l}\text { Uma pequena longa } \\
\text { história. }\end{array}$ & 8 & 175 & $\begin{array}{l}\text { Sucessão dos ancestrais humanos, começando } \\
\text { com o Teco, na qual aspectos do ambiente } \\
\text { como presas e predadores e mudanças } \\
\text { ambientais, além de eventos de acasalamento e } \\
\text { migração para além da África. }\end{array}$ & $\begin{array}{l}\text { Os humanos atuais são fruto de um processo } \\
\text { evolutivo que ocorre pela ação de efeitos } \\
\text { ambientais e populacionais. }\end{array}$ \\
\hline $\begin{array}{l}\text { Manequin challenge } A \\
\text { teoria } \quad \text { sintética } \\
\text { evolutiva }\end{array}$ & 71 & 29 & $\begin{array}{l}\text { A teoria sintética evolutiva é explicada a partir } \\
\text { de cartazes com conceitos científicos, } \\
\text { segurados por garotas em poses de manequins, } \\
\text { enquanto a câmera passeia pelo ambiente em } \\
\text { plano sequência. }\end{array}$ & $\begin{array}{l}\text { A Teoria sintetiza evolutiva tem sua } \\
\text { fundamentação científica em Darwin e o acréscimo } \\
\text { de conhecimentos que foram incorporados ao longo } \\
\text { do séc. XX e atualmente é a base para estudos em } \\
\text { Biologia Evolutiva. }\end{array}$ \\
\hline $\begin{array}{l}\text { Retrato molecular do } \\
\text { Brasil. }\end{array}$ & 36 & 290 & $\begin{array}{l}\text { Dois estudantes conversando sobre a } \\
\text { diversidade em humanos são auxiliados por } \\
\text { uma bióloga, que apresenta conceitos sobre a } \\
\text { diversidade genética e a composição das } \\
\text { populações brasileiras. }\end{array}$ & $\begin{array}{l}\text { As diferenças étnicas entre as pessoas tem como } \\
\text { base genética mínimas variações no DNA, o que } \\
\text { indica que todos da espécie humana fazem parte de } \\
\text { uma única raça (a humana), o que torna o racismo } \\
\text { algo incoerente do ponto de vista biológico. }\end{array}$ \\
\hline $\begin{array}{l}\text { Evolução do } \\
\text { pensamento humano. }\end{array}$ & 13 & 246 & $\begin{array}{l}\text { Em um telejornal, a apresentadora entrevista } \\
\text { uma pesquisadora especializada na evolução } \\
\text { do pensamento humano. }\end{array}$ & $\begin{array}{l}\text { O pensamento humano, caracterizado pela projeção } \\
\text { de ações e abstração de fenômenos, tem suas bases } \\
\text { evolutivas na aquisição e desenvolvimento da } \\
\text { linguagem. }\end{array}$ \\
\hline $\begin{array}{l}\text { Os primeiros } \\
\text { americanos. }\end{array}$ & 94 & 238 & $\begin{array}{l}\text { Duas amigas conversam sobre o tema da aula } \\
\text { de "Evolução" que uma delas perdeu: a } \\
\text { conquista das Américas pelos humanos. }\end{array}$ & $\begin{array}{l}\text { O homem chegou as Américas pelo estreito de } \\
\text { Beringer, a partir de uma corrente migratória saída } \\
\text { da África, há cerca de } 20 \text { mil anos, e que enfrentou } \\
\text { os obstáculos produzidos pelo clima frio da Ásia }\end{array}$ \\
\hline A evolução da barba. & 80 & 39 & $\begin{array}{l}\text { Sequência de imagens com um garoto com } \\
\text { diferentes combinações de barba, bigode e } \\
\text { rosto sem pelos e discussão de amigas sobre a } \\
\text { aversão delas por homens com pelos. }\end{array}$ & $\begin{array}{l}\text { Homens com barba e pelos são recusados pelas } \\
\text { mulheres. }\end{array}$ \\
\hline $\begin{array}{l}\text { Homossexualidade e a } \\
\text { Bíblia. }\end{array}$ & 0 & 120 & $\begin{array}{l}\text { Dois garotos com símbolos do movimento } \\
\text { LGBTQAI+ em seus corpos interagem como } \\
\text { se tivessem um relacionamento, enquanto uma } \\
\text { narrativa em off apresenta conceitos sobre a } \\
\text { Bíblia e a homossexualidade. }\end{array}$ & $\begin{array}{l}\text { A Bíblia não discrimina homossexuais, mas sim } \\
\text { sua interpretação enviesada e ao longo da história } \\
\text { da humanidade a atração sexual entre indivíduos do } \\
\text { mesmo sexo passou por momentos com maior ou } \\
\text { menor aceitação, esta última muitas vezes reflexo } \\
\text { de abordagens Criacionistas. }\end{array}$ \\
\hline Dedos e esportes. & 71 & 102 & $\begin{array}{l}\text { Seis homens, praticantes ou não de esportes, } \\
\text { tem a relação indicador-anelar avaliada. }\end{array}$ & $\begin{array}{l}\text { A proporção anelar-indicador em homens que } \\
\text { gostam de praticar esportes esperada é menor que } \\
1,0 \text {, porém os resultados obtidos indicaram que isso } \\
\text { necessariamente não se aplica à realidade. }\end{array}$ \\
\hline
\end{tabular}

Fonte: Autores.

O predomínio dos planos fechados, apresentados na Tabela 2, é melhor observado na Figura 1. De fato, das dez produções, somente uma utilizou planos abertos com mais frequência. Os planos fechados são comumente utilizados em documentários (Galego \& Pereira, 2020), gênero cinematográfico frequentemente associado ao discurso científico (Peres, 
2007; Passou et al., 2011).

Figura 1. Porcentagem de utilização de planos fechados em abertos em produções audiovisuais com a temática "evolução humana" realizadas por discentes do curso de Licenciatura em Ciências Biológicas de uma universidade pública brasileira.

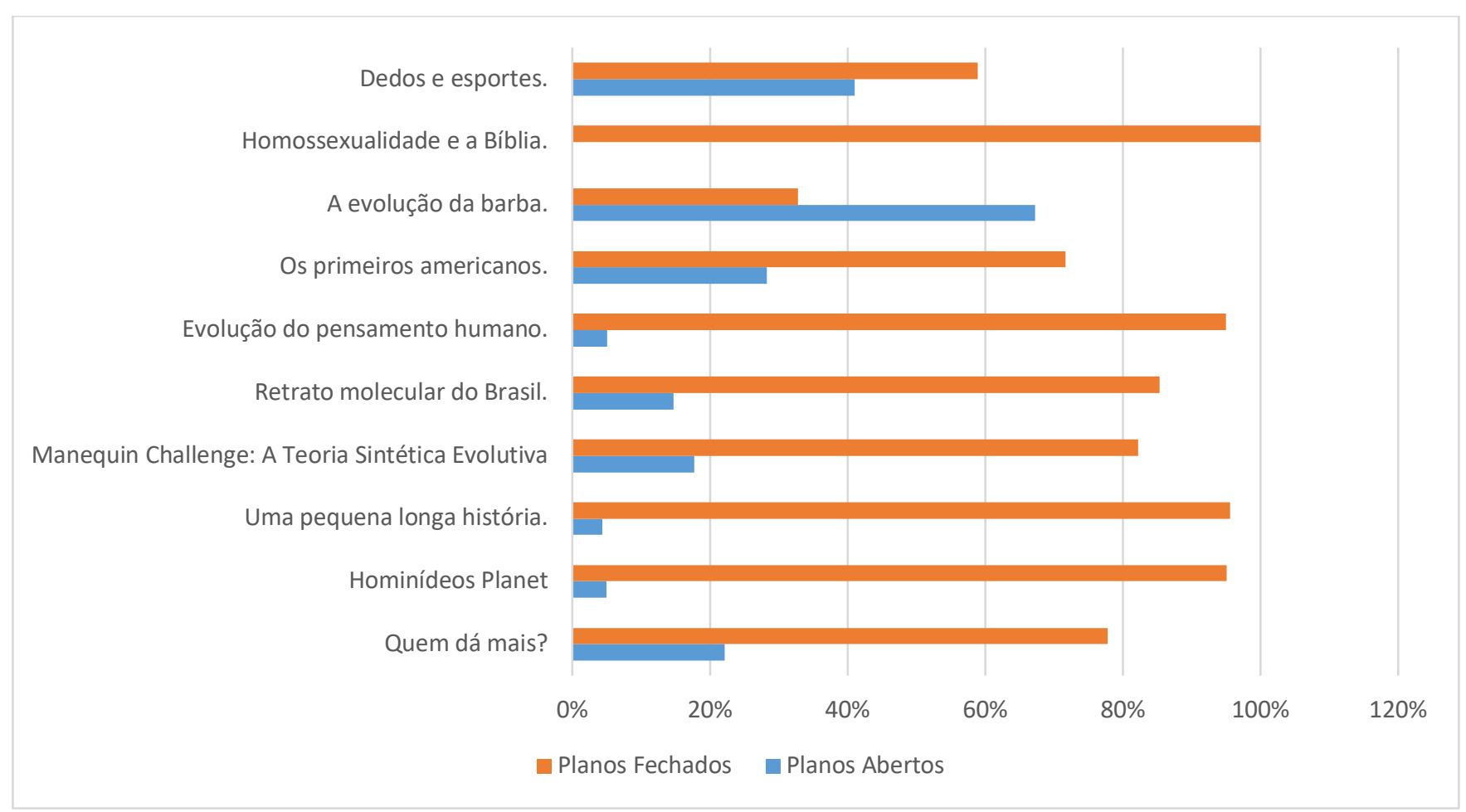

Fonte: Autores.

As produções dos futuros professores apresentaram grande diversidade em relação às escolhas narrativas e de gênero cinematográfico, que incluem drama/romance/outras estruturas narrativas, jornal/documentário/entrevista, animação e plano sequência.

A maioria das produções audiovisuais realizadas pelos futuros professores apresentou grande aderência com os conceitos científicos aceitos para a evolução humana, com exceção de duas delas: Quem dá mais? e Evolução da barba. As duas apresentam conceitos muito próximos ao senso comum e permeados de uma perspectiva sexista (ambas discutem questões de morfologia e biologia reprodutiva) e focam mais na dimensão narrativa da produção do que nos conceitos científicos relacionados à biologia evolutiva, utilizando muitos planos abertos (22\% e $67 \%$, respectivamente). Estudos brasileiros sobre o ensino da Evolução Biológica (Bizzo, 1994; Santos \& Bizzo, 2000; Santos, 2002; Oleques, Bartholomei \& Boer, 2011; Souza \& Dorvillé, 2014) têm demonstrado a presença de uma série de equívocos quanto à interpretação de processos evolutivos entre alunos e professores de Ciências e Biologia.

Tavares, Amorin e Abreu (2016) sugerem uma manutenção de metodologias tradicionais de ensino de Evolução Biológica, o que dificulta a compreensão de conceitos fundamentais à Biologia, por um lado, mas que confrontam com outras questões de natureza filosófica como nossa origem, e, em alguns pontos, antagonizam com os pressupostos Criacionistas (Reis et al., 2009). Outros estudos (Licatti \& Diniz, 2005; Corrêa et al., 2010) indicam que os professores tem dificuldade em discutir os conceitos sobre Evolução Biológica com os alunos, e alguns apresentam uma concepção Lamarckista sobre Evolução (Tidon \& Lewontin, 2004), visão esta que foi superada pela ciência há mais de cem anos.

Diversos são os fatores que colaboram para esta configuração nas escolas e universidades brasileiras, tais como o pouco tempo disponibilizado para o ensino de Evolução Biológica (Tidon \& Lewontin, 2004); a visão fragmentada apresentada nos 
livros didáticos, portanto sem relacionar com as demais áreas da biologia (Tidon \& Vieira, 2009); dificuldade por parte dos professores em compreender o processo, principalmente devido a lacunas na formação inicial e continuada (Tidon \& Lewontin, 2004), além da influência de crenças religiosas no conhecimento científico (Reis et al., 2009).

Dessa forma, o ensino de Evolução Biológica é consideravelmente alvo de confusões conceituais, obstáculos didáticos, epistemológicos e religiosos entre professores e alunos. Além disso, ainda é pautado em uma perspectiva tradicional de transmissão de conhecimentos, embasada na formação metafísica e da racionalidade técnica.

Segundo Goedert et al. (2006), deve-se superar as metodologias de ensino com abordagem tradicional a partir de estratégias didático-pedagógicas diversificadas e que podem ser direcionadas tanto aos professores em exercício (formação continuada), quanto aos futuros professores, os alunos-licenciandos (formação inicial).

A despeito das múltiplas possibilidades metodológicas de ensino que o campo de conhecimento da Biologia oferece, destaca-se a utilização de produções audiovisuais no contexto escolar.

É importante ressaltar que, de acordo com a Lei 13.006 de 26 de junho de 2014, é obrigatório a exibição de duas horas mensais de filmes de produção nacional nas redes de ensino da educação básica no Brasil (2014):

“[...] a exibição de filmes de produção nacional consistirá componente curricular complementar integrado à proposta pedagógica da escola, sendo a sua exibição obrigatória, por no mínimo, 2 (duas) horas mensais."

As produções audiovisuais contribuem para que o aluno construa suas reflexões sobre os aspectos conceituais, além de possibilitar a integração destes com os procedimentais e atitudinais, bem como colaborar no desenvolvimento de habilidades (Coll \& Martin, 2004) e possibilitar_problematização de diferentes questões sob novos pontos de vista (Fernandes \& Garcia, 2017). Nesse sentido, Santos e Kloss (2010, p. 8) afirmam que:

“[...] a linguagem do vídeo possibilita o professor deixar de ser um informador, passando a ser um mediador que provoca a autonomia do aluno. A imagem mostra-se mais eficaz que a palavra na hora de provocar emoções. Sendo assim, o vídeo desempenha um papel importante com sua capacidade de provocar emoções e sensações."

Historicamente, as produções audiovisuais têm sua inspiração nas mídias de massa (cinema, televisão e vídeo, sobretudo) que, por sua vez, desencadearam a necessidade pela imagem nas populações humanas em suas diversas manifestações culturais, além de serem importantes veículos para disseminação do conhecimento e da informação (Carvalho, 2003). O ambiente escolar agrega esses dois aspectos das mídias de massa, sendo o cinema uma das utilizadas na prática docente em sala de aula (Duarte \& Gonçalvez, 2014).

O interesse do cinema em sala de aula não é recente, pois há relatos de pensadores da educação da década de 20 e 30 que já apresentavam o uso da fotografia em movimento como recurso importante para o enriquecimento do ensino, principalmente relacionado à instrução e a reprodução da informação (Barros, 1997). Desse período também emergem os primeiros trabalhos que relacionam a interface Cinema e Educação que apresentavam diversos benefícios em se utilizar filmes como importante ferramenta no desenvolvimento de estratégias de ensino.

Alguns fatores são favorecedores da utilização do cinema no contexto escolar (Abud, 2003), como a enorme atração que a produção fílmica exerce, o fácil acesso às produções cinematográficas e as políticas públicas de investimento em recursos de natureza audiovisual são alguns dos aspectos que beneficiam a relação cinema-escola.

Carvalho (2003) afirma que a linguagem cinematográfica pode ser utilizada em processos pedagógicos além da visão tradicional do cinema como simples material ilustrativo e instrucional. Uma das maneiras de se aproveitar das múltiplas possibilidades do cinema enquanto recurso didático é lançar mão de técnicas cinematográficas para o ensino de um ou mais conteúdos de forma multidisciplinar. 
Segundo Fernandes e Garcia (2017), o cinema, em muitos casos, amplia as possibilidades de leitura, permitindo a problematização de diferentes questões sob novos pontos de vista. Ainda, segundo Santos e Kloss (2010, p. 6):

"[...] o vídeo pode servir para introduzir um novo assunto, para despertar a curiosidade, a motivação para novos temas, facilitar o desejo de pesquisa nos alunos e do conteúdo didático. Ele pode ser um grande diferencial no processo de informação, e se usado de forma coerente, poderá ser aproveitado todo o seu potencial educativo."

Artis (2011) ressalta que a limitação financeira não é um real empecilho para a produção audiovisual, pois uma ideia boa pode gerar um bom filme. De fato, as experiências de Pereira et al. (2014), Galego et al. (2014) e Ferreira e Costa (2016) com alunos-licenciandos dos cursos de Ciências Biológicas, Física, Química e Matemática da UFTM demostraram que os mesmos apresentam alto potencial para a produção cinematográfica e que diferentes aprendizagens podem ser geradas por meio da proposição de produções audiovisuais.

\section{Considerações Finais}

A análise realizada mostra que as produções audiovisuais representam ferramenta didática apropriada para a divulgação científica por terem ampla intertextualidade, sendo uma forma de substituir metodologias consideradas tradicionais como o livro didático. A utilização desse tipo de ferramenta didática pode aumentar o desenvolvimento intelectual do aluno, enquanto valoriza sua interatividade, por se tratar de produções não só de caráter visual, mas uma forma de construir conhecimentos e sensibilizar, cooperando para o desenvolvimento de práticas escolares relacionadas ao nível estético. Diante disso, os materiais audiovisuais se colocam como importante ferramenta didática, pois confiscam e sustentam a atenção do espectador com maior eficiência do que meios didáticos considerados tradicionais

Os vídeos analisados foram produzidos por discentes, dando outra dimensão para o uso de filmes, que além de serem usados colocando o aluno como espectador também pode colocá-lo como produtor, fazendo uso desse meio para explorar seus conhecimentos e divulgar o que considera apropriado.

É necessário ressaltar que empregar vídeos, como material de apoio, é um modo de agregar mais dinamismo à aula, porém não deve ser visto como substituto do docente ou para tampar buracos. Nesse sentido, é imprescindível interesse por parte do professor, pois é a partir do seu direcionamento ao aluno que os audiovisuais podem se tornar ferramentas pedagógicas para o ensino de qualquer conhecimento, inclusive e especialmente da Evolução Humana.

Dessa forma, compete ao professor a escolha da melhor aplicação dos recursos visuais em sua sala de aula, considerando seu público-alvo e sua disciplina, mas também, fundamentando-se na análise anterior do recurso, para que exista afinidade com o conteúdo promovido.

\section{Referências}

Abud, K. M. A. (2003) A construção de uma didática da história: algumas ideias sobre a utilização de filmes no ensino. História, $22,183-193$.

Artis, A.Q. (2011) Silêncio: Filmando. Elsevier, 2011.

Barros, A. X. M.(1997) O Cinematográfo Escolar: I Conferência Nacional de Educação (1927: Curitiba). INEP.

Bizzo, N. M. V. (1994) From Down House landlord to Brazilian highschool-students - what has happened to evolutionary knowledge on the way? Journal of Research in Science Teaching, 31, 537-556.

Borges, M. N., Miranda, R. R. M., Leal, R. C. O. \& Rodrigues, T. D. (2020) Cinema e consciência: desafios da formação docente. Revista Thema, 17 (2), 495508 .

Brasil, Ministério da Educação. (2002) Diretrizes Curriculares Nacionais para os Cursos de Graduação em Ciências Biológicas. Parecer CES/CNE 1.301/2001, homologação publicada no DOU 07/12/2001, Seção 1, p. 25. Resolução CES/CNE 07/2002, publicada no DOU 26/03/2002, Seção 1, p. 13, 2002. 
Brasil. Ministério da Educação, Secretaria da Educação Média e Tecnológica. (1999). Parâmetros Curriculares Nacionais: Ensino Médio.

Brasil. Ministério da Educação. (2006) Orientações Curriculares para o Ensino Médio. http://portal.mec.gov.br/seb/arquivos/pdf/book_volume _02_internet.pdf.

Carvalho, E. J. G. (2003) Conhecimento da história e da educação: o cinema como fonte alternativa. Revista Comunicações, $10,183-193$.

Coll, C. \& Martin, E. (2004) Aprender conteúdos e desenvolver capacidades. Artmed.

Corrêa, A. L., Araújo, E. N. N., Meglhioratti, F. A. \& Caldeira, A. M. A. (2010) História e filosofia da biologia como ferramenta no ensino de evolução na formação inicial de professores de biologia. Filosofia e História da Biologia,5, 217-237.

Cruz, B. S. \& Galego, L. G.C. (2020) De um aperto de mão a um beijo roubado: análise semiótica de "Eu não quero voltar sozinho. Revista Voos Polidisciplinar, 7, 118-132.

Duarte, R., Gonçalvez, B. M. A. P. (2014) Escola e audiovisual no Brasil. In: Barbosa, M. C. S., Santos, M. A. Escritos de Alfabetização Visual. Libretos.

Fantin, M. (2014) Audiovisual na escola: abordagens e possibilidades. In: M. C. Barbosa \& M. A. Santos (orgs.) Escritos de alfabetização audiovisual. Porto Alegre: Libretos.

Fernandes, A. H. \& Garcia, P. B. (2017) O cinema como formação: a escola como mediadora da relação entre jovens e filmes. Educação Temática Digital, 19, 384-399.

Ferreira, B. \& Costa, V. (2016) O cinema na formação de professores: interfaces com o Pibid Química. Iniciação \& Formação Docente, 3, 1-14.

Galego, L.G.C., Costa, V.G., Rodrigues, V. C.S. \& Pereira, F.L. (2014) Técnicas cinematográficas e aprendizagens e o programa de educação tutorial (PET)Ciências da Natureza e Matemática (UFTM). RELICI, 1 (1), 15-22.

Galego, L.G.C. \& Pereira, F. L. P. (2020) Planos, sequências e abstrações: a cinematografia e a educação. In: M. A. A. Silva. Formação de Professores: perspectivas teóricas e práticas na formação docente 2. Atena Editora.

Goedert, L., Delizoicov, N. C. \& Rosa, V. L. (2003) A formação de professores de Biologia e a prática docente - o ensino de evolução. Atas do IV ENPEC. Recuperado de https://fep.if.usp.br/ profis/arquivo/encontros/enpec/ivenpec/Arquivos/Orais/ORAL012.pdf.

Goedert, L., Leyser, V. \& Delizoicov, N.C. (2006) A formação do professor de Biologia na UFSC e o Ensino de Evolução Biológica. Contexto \& Educação, $76,13-41$.

Licatti, F. \& Diniz, R. E. S. (2005) Concepções de professores de biologia sobre o ensino de evolução biológica em nível médio. Atas do V ENPEC. Recuperado de http://abrapecnet.org.br/atas_enpec/venpec/conteudo/artigos/3/pdf/p360.pdf.

Merrell. F. (2012) A Semiótica de Charles S. Peirce Hoje. Ed. Unijuí.

Migliorin, C. (2015) Inevitavelmente Cinema: educação, política e mafuá. Azougue.

Napolitano, M. (2011) Como usar o cinema em sala de aula. Contexto.

Oleques, L.C., Bartholomei-Santos, M. L. \& Boer, N. (2011) Evolução biológica: percepções de professores de biologia. Revista Electrónica de Enseñanza de las Ciencias, 10, 243-264.

Passou, A. S., Melo, W. V., Andrade, L. \& Pereira, R. M. M. (2011) Fatores que influenciam na utilização de filmes como recurso didático pelos docentes de ciências. Anais do VIII ENPEC. http://abrapecnet.org.br/atas_enpec/viiienpec/resumos/R1240-1.pdf.

Pereira, F. L., Costa, V. G., Rodrigues, V. C. S. \& Galego, L. G. C. (2014). Cinematografia e formação inicial de professores: relato de experiência com alunos do PIBID Matemática (UFTM). RELICI, 1(1), 9-14.

Peres, S. S. (2007) O formato e a linguagem dos documentários produzidos sobre a cidade de São Paulo. XXX Congresso brasileiro de ciências da comunicação. Recuperado de http://www.intercom.org.br/papers/nacionais/2007/resumos/R0626-1.pdf.

Reis, P., Braga, R., Lima, V. \& Santos, A.L. (2009) Reflexões sobre o ensino de evolução e suas consequências diante da laicidade estatal. Anais do III Encontro Estadual de Didática e Prática de Ensino (EDIPE). http://www.ceped.ueg.br/anais/IIIedipe/pdfs/2_trabalhos/gt04_fisica_quimica_bi ologia_ciencias/trab_gt04_reflexoes_sobre_o_ensino_de_evolucao.pdf.

Santos, P. R. \& Kloss. S. (2010) A criança e a mídia: a importância do uso do vídeo em escolas de Joaçaba - SC. In: Anais do XI Congresso de ciências da comunicação da região sul. http://www.intercom.org.br/papers/regionais/sul2010/resumos/R20-0957-1.pdf.

Santos, S. (2002) Evolução Biológica: ensino e aprendizagem no cotidiano da sala de aula. Annablume.

Santos, S. C., \& Bizzo, N. M. V. (2000). O ensino e a aprendizagem de evolução biológica no quotidiano da sala de aula. In Coletânea. FEUSP.

Scheifele, A., Corazza, M. J. \& Justiba, L. A. D. (2020) Concepções de professores de biologia em formação inicial sobre evolução biológica. Research, Society and Development, 9(8), 1-23.

Silva, D. P., Vilela, D. H. L. A., Oliveira, F. T., Comassetto, I. \& Santos, R. M. (2021) Uso de filmes como estratégia no ensino de bioética. Research, Society and Development, 10(6), 1-9. 
Research, Society and Development, v. 10, n. 8, e22310817212, 2021

(CC BY 4.0) | ISSN 2525-3409 | DOI: http://dx.doi.org/10.33448/rsd-v10i8.17212

Sousa, E. C. F. \& Dorvillé, L. F. M. (2014) Ensino de evolução biológica: concepções de professores protestantes de ciências e biologia. Revista da SBenBio, $7,1855-1866$

Sousa, M. C. F., Cicuto, C. A. T. \& Lucchese, M. M. (2020) O cinema no Ensino de Ciências da Natureza: análise do filme "As aventuras de Sammy". Research, Society and Development, 9(9), 1-13.

Tavares, N. K. A., Amorin, F. P. \& Abreu, V. A. (2016) Evolucionismo e criacionismo nos livros didáticos do ensino fundamental de escolas públicas e privadas: uma avaliação sobre abordagens. Acta Scientia Biologica, 1, 75-90.

Tidon, R. \& Lewontin, R. C. (2004). Teaching evolutionary biology. Genetics and Molecular Biology, 27 (1), 124-131.

Tidon, R. \& Vieira, E. (2009) O ensino da Evolução Biológica: um desafio para o século XXI. ComCiência, 107.

Veiga, A. P. V., Ribeiro, B. C., Padova, L. C. \& Ghisleni, T. S. (2020) Interdisciplinaridade na produção de conteúdos educacionais: a relação teoria e prática. Research, Society and Development, 21 (1), 1-11. 